\title{
Parameters associated with persistent airflow obstruction in chronic severe asthma
}

\author{
D. Bumbacea*, D. Campbell ${ }^{\#}$, L. Nguyen\#, D. Carr", P.J. Barnes", D. Robinson", K.F. Chung
}

Parameters associated with persistent airflow obstruction in chronic severe asthma. D. Bumbacea, D. Campbell, L. Nguyen, D. Carr, P.J. Barnes, D. Robinson, K.F. Chung. (C) ERS Journals Ltd 2004.

ABSTRACT: The significance of severe airflow obstruction in severe asthma is unclear. The current study determined whether severe airflow obstruction is related to inflammatory or structural changes in the airways.

Patients with severe asthma from a tertiary referral clinic were divided into two groups according to their postbronchodilator forced expiratory volume in one second (FEV1): severe persistent airflow limitation (FEV1 $<\mathbf{5 0} \%$ predicted; group $S ; n=37)$ and no obstruction (FEV1 $>80 \%$ pred; group $N$; $n=29$ ). Smoking history, atopic status, lung function tests, exhaled NO, blood eosinophil count, quality of life scores using St George's Respiratory Questionnaire and high resolution computed tomography (HRCT) of the lungs were assessed.

Patients from group $\mathrm{S}$ were older and had longer disease duration. There was no difference in smoking history, atopic status, hospital admissions, quality of life scores and amount of treatment with inhaled or oral corticosteroids. Exhaled NO and peripheral blood eosinophils were higher in group $S(21.0 \pm 2.4$ versus $12.8 \pm 2.3 \mathrm{ppb} ; 0.41 \pm 0.06$ versus $0.15 \pm 0.03 \times 10^{9}$ cells $\cdot \mathrm{L}^{-1}$, respectively). HRCT scores for bronchial wall thickening and dilatation were higher in group $S$ with no differences in air trapping. Peripheral blood eosinophilia and bronchial wall thickening on HRCT scan were the only parameters significantly and independently associated with persistent airflow obstruction.

Patients with severe asthma and irreversible airflow obstruction had longer disease duration, a greater inflammatory process and more high resolution computed tomography airway abnormalities suggestive of airway remodelling, despite being on similar treatments and experiencing equivalent impairment in quality of life. Eur Respir J 2004; 24: 122-128.
*Clinica de Pneumologie, Institutul National de Pneumologie "Marius Nasta", Universitatea de Medicina si Farmacie, Carol Davila, Bucharest, Romania. ${ }^{\#}$ Asthma and Allergy Research Group, Royal Brompton and Harefield NHS Trust, and National Heart and Lung Institute, Imperial College, London, UK.

Correspondence: K.F. Chung, National Heart and Lung Institute, Imperial College School of Medicine, Dovehouse Street, London SW3 6LY, UK.

Fax: 442073518126

E-mail: f.chung@imperial.ac.uk

Keywords: Airway remodelling airway thickening

eosinophils

severe asthma

\section{Received: July 72003}

Accepted after revision: March 152004

This work was supported by the Royal Brompton and Harefield NHS Trust, and European Respiratory Society Research Fellowships to D. Bumbacea and L. Nguyen.
Asthma is a chronic inflammatory disorder of the airways characterised by recurrent symptoms associated with airflow limitation and by bronchial hyperresponsiveness. Inhaled corticosteroids, which suppress airway inflammation, are efficient in reducing symptoms and exacerbations, and often normalise lung function. However, a proportion of patients with asthma are not controlled and have persistent symptoms, recurrent exacerbations and/or persistent airflow limitation despite using high doses of inhaled corticosteroids (and often oral corticosteroids) and long-acting bronchodilators. This small proportion of asthmatics, labelled with difficult/therapyresistant [1] or refractory [2] asthma, experience greater morbidity with severe derangement of quality of life and the use of a disproportionate amount of healthcare resources [3].

The clinical spectrum of severe asthma is variable, ranging from life-threatening attacks superimposed on disease-free periods (brittle asthma [4]) to severe chronic persistent symptoms. Patients may have normal lung function between exacerbations (reversible disease) or persistent, sometimes severe, airflow limitation that may only be partially reversible to asthma medication, such as $\beta_{2}$-adrenergic bronchodilators or corticosteroids. Persistent airway inflammation with eosinophilic or neutrophilic predominance [5,6], features of airway remodelling [7], airway inflammation with remodelling in the small airways [8] or a combination of the above have

For editorial comments see page 8. been described. The causes of persistent airflow obstruction in chronic severe asthma are unknown but may be related to the presence of airway wall remodelling, with increased airway smooth muscle mass and airway wall fibrosis, or to persistent airway inflammation that could lead to persistent release of bronchoconstrictor mediators. In a recent study, a strong association between sputum eosinophilia and persistent airflow obstruction in asthmatic patients has been reported [9]. However, a forced expiratory volume in one second (FEV1) of $<75 \%$ predicted was used as a cut-off level for severe airflow obstruction.

In order to further unravel the associations between severe asthma with airflow obstruction, the current study compared various characteristics of severe asthma patients with severe persistent airflow obstruction to those with normal lung function, including noninvasive measures of inflammation using exhaled NO measurements and blood eosinophil counts, and a measure of airway wall thickness as assessed by high resolution computed tomography (HRCT). A more severe value of $50 \%$ FEV1 predicted was used as the cut-off point.

\section{Methods}

\section{Severe asthma protocol}

Patients referred to the Royal Brompton Hospital, London, with a presumed diagnosis of severe asthma underwent a 
structured assessment protocol as to diagnosis and treatment. Asthma was diagnosed on the basis of chronic symptoms and/or of recurrent exacerbations together with previously documented reversible airflow obstruction of $>15 \%$ either spontaneously or with treatment. Asthma was considered severe because of persistent symptoms and/or recurrent exacerbations despite the use of high dose inhaled steroid therapy, and often in addition to needing regular oral steroid therapy. For this study, the data from the first 175 patients referred to the severe asthma protocol were examined from the database. The systematic assessment of the first 100 patients of difficult-to-treat asthma has recently been reported [10] and the current authors have also described the distribution of exhaled nitric oxide measurements in the first 52 patients [11].

\section{Patient characteristics}

For the purposes of the present study, two groups of patients were obtained from the current authors' database: one with severe persistent airflow obstruction (group S) as defined by a postbronchodilator FEV $1<50 \%$ pred $(n=51)$, and the other without airflow obstruction (group $\mathrm{N}$ ) with a postbronchodilator FEV1 $>80 \%$ pred $(n=41)$. These were postbronchodilator FEV1, and had not varied by $>10 \%$ when repeated within 3-6 months. All patients were assessed during a 3-day hospital admission when the history, clinical and laboratory findings regarding the diagnosis of asthma were reviewed. Patients were reviewed again 3-6 months later when the diagnosis of asthma was either confirmed or refuted. In this way, 14 were excluded from group $\mathrm{S}$ and 12 from group $\mathrm{N}$. In those in group $\mathrm{S}$ that were excluded for the presence of significant concomitant diseases, these included: chronic obstructive pulmonary disease (COPD) $(n=5)$, allergic bronchopulmonary aspergillosis $(\mathrm{n}=2)$, Churg Strauss syndrome $(n=1)$, hypereosinophilic syndrome $(n=1)$, bronchiolitis $(n=1)$, bronchiectasis $(n=1)$, pulmonary artery stenosis $(n=1)$, significant exposure to coal dust in an exminer $(n=1)$ and refusal to take oral corticosteroids $(n=1)$. Patients were diagnosed with COPD on the basis of a lack of previous history of reversible airflow obstruction. Patients that were excluded from group $\mathrm{N}$ did not fit the criteria for severe asthma and had mild-to-moderate asthma. Therefore, using the criteria for this study, the analysis was performed in $37 \mathrm{~S}$ and $29 \mathrm{~N}$ patients.

\section{Measurements and investigations}

FEV1 and forced vital capacity (FVC) were measured using a spirometer (Erich Jaeger UK Ltd, Market Harborough, UK) using published predicted values [12]. Diffusing capacity to carbon monoxide and lung volumes (residual volume (RV), and total lung capacity (TLC)) were measured with a body plethysmograph (Master Lab; Erich Jaeger UK Ltd). The maximal bronchodilator response was determined $30 \mathrm{~min}$ after inhaling salbutamol $(400 \mu \mathrm{g})$ after discontinuation of short-acting $\beta_{2}$-agonist for $4 \mathrm{~h}$, and of long-acting $\beta$-agonist for at least $12 \mathrm{~h}$. Peak flow measurements were recorded in the morning and in the evening, and peak flow variability over 2 weeks was expressed as amplitude mean per cent [13]. Patients continued with their maintenance bronchodilator therapy, such as long-acting $\beta$-agonists or subcutaneous terbutaline, while performing these peak flow measurements.

Exhaled NO was measured with a chemiluminescence analyser (model LR2000; Logan Research Ltd., Rochester, UK), as previously described [11]. The mean of two consecutive measurements was recorded. Quality of life was assessed using the St George's Respiratory Questionnaire [14]. The presence of atopy was defined by the presence of a positive skin-prick test to at least two aeroallergens (house dust mite, mixed grass pollen, cat dander and dog dander).

HRCT scans were performed on full inspiration and at endexpiration using an Imatron Ultrafast CT scanner (Imatron, San Francisco, CA, USA). The abnormalities of intrapulmonary bronchi (wall thickening and dilatation) and the degree of air trapping were evaluated according to a previously published score system [15]. Each pulmonary lobe was evaluated for bronchial wall thickening and dilatation (score 0-3) and for air trapping (score 0-2). The total extent of changes for each abnormality for each patient was obtained on a 19-point scale $(0-18)$ for bronchial wall thickening and dilatation and a 13-point scale $(0-12)$ for air trapping.

\section{Statistical analysis}

Data were expressed either as mean \pm SEM and compared using the unpaired t-test for normally-distributed continuous variables, or alternatively as median (interquartile range) for ordinal variables and for non-normally distributed continuous variables and compared using the Mann-Whitney U-test. Proportions were compared using the Chi-squared test. Logistic regression analysis was used to compute estimated OR for the presence of severe airflow limitation for each factor found significantly different between the two groups. Multiple logistic regression analysis was used to compute the adjusted OR (for possible confounding factors) and to assess the independence of the relation between each factor and the presence of severe persistent airflow obstruction. The following contrasts were used: ex- or current smoker versus never smoker, atopic versus nonatopic, age of asthma onset $(\geqslant 18$ versus $<18$ yrs), peak expiratory flow (PEF) variability $(>10 \%$ versus $<10 \%)$, FEV1 reversibility $(\geqslant 9 \%$ versus $<9 \%$ ), exhaled NO ( $\geqslant 10 \mathrm{ppb}$ versus $<10 \mathrm{ppb})$, peripheral blood eosinophils $\left(>450\right.$ versus $\left.\leqslant 450 \times 10^{6} \cdot \mathrm{L}^{-1}\right)$, total immunoglobulin $\mathrm{E}(\mathrm{IgE})\left(>100\right.$ versus $\left.\leqslant 100 \mathrm{IU} \cdot \mathrm{mL}^{-1}\right)$, presence versus absence of bronchial wall thickening, bronchial dilatation and air-trapping on HRCT. Statistical significance was defined by a $p$-value of $<0.05$.

Because of the well-known association between smoking and persistent airflow obstruction, and because of the high percentage of current or exsmokers in the population, the same analysis as for the whole group in nonsmokers (22 in group $\mathrm{S}$ and 23 in group $\mathrm{N}$ ) and for the $<10$ pack-yr history ( 30 in group $\mathrm{S}$ and 27 in group $\mathrm{N}$ ) was performed.

\section{Results}

\section{Patient demographics}

Patients with severe persistent airflow limitation were older $(\mathrm{p}<0.001)$ and more frequently male $(\mathrm{p}<0.05)$, although females dominated both groups (table 1). The age at diagnosis was not different between groups, but the duration of disease was longer in group $\mathrm{S}(\mathrm{p}<0.001)$. The proportion of smokers (current and past) was higher in group $\mathrm{S}$, but this did not achieve statistical significance. Comparisons of level of tobacco consumption (expressed as pack-yrs) between the two groups was not significant, with seven patients in group $\mathrm{S}$ and two patients in group $\mathrm{N}$ with $\geqslant 10$ pack-yrs tobacco consumption. Although there was no difference in hospital 
Table 1.-Demographics, history of asthma and asthma treatment

\begin{tabular}{|c|c|c|c|}
\hline & Group S & Group N & p-value \\
\hline Patients $\mathrm{n}$ & 37 & 29 & \\
\hline Age yrs & $44 \pm 2$ & $30 \pm 2$ & $<0.001$ \\
\hline Male sex & $35.1 \%$ & $13.8 \%$ & $<0.05$ \\
\hline Age at diagnosis yrs & $14(5-32)$ & $18(3-18)$ & NS \\
\hline Asthma duration yrs & $25 \pm 2$ & $15 \pm 2$ & $<0.001$ \\
\hline Smoking $\%$ current and past smokers & $40.5 \%$ & $20.7 \%$ & NS \\
\hline Tobacco consumption pack-yrs & $0(0-5.75)$ & $0(0-0)$ & NS \\
\hline Atopy $\%$ & $54.1 \%$ & $55.2 \%$ & NS \\
\hline Hospital admissions for asthma ${ }^{\#}$ & $2(1-3.5)$ & $3(1-4)$ & NS \\
\hline History of mechanical ventilation & $43.2 \%$ & $17.2 \%$ & $<0.05$ \\
\hline Current prednisolone dose $\mathrm{mg} \cdot \mathrm{day}^{-1}$ & $17.1 \pm 3.0$ & $16.6 \pm 2.5$ & NS \\
\hline Oral steroid short-course in the last $\mathrm{yr}^{\top}$ & $4(3-5)$ & $5(4-5)$ & $<0.05$ \\
\hline Inhaled steroid dose $\mathrm{mg} \cdot \mathrm{day}^{-1} \mathrm{BDP}$ equivalent ${ }^{+}$ & $3.4 \pm 0.4$ & $3.4 \pm 0.3$ & NS \\
\hline Theophylline $\mathrm{mg} \cdot \mathrm{day}^{-1}$ & $416 \pm 80$ & $393 \pm 68$ & NS \\
\hline Inhaled long-acting $\beta_{2}$-agonist puffs $\cdot$ day $^{-1}$ & $3.3 \pm 0.4$ & $3.8 \pm 0.5$ & NS \\
\hline Inhaled short-acting $\beta_{2}$-agonist puffs day $^{-1}$ & $10.3 \pm 1.5$ & $6.6 \pm 1.3$ & NS \\
\hline Subcutaneous terbutaline $\%$ users & $10.8 \%$ & $41.4 \%$ & $<0.01$ \\
\hline Nebulised rapid-acting $\beta_{2}$-agonist $\%$ users & $32.4 \%$ & $55.2 \%$ & NS \\
\hline
\end{tabular}

Data are presented as $\mathrm{n}$, percentage, mean \pm SEM or median (interquartile range) unless stated otherwise. BDP: beclomethasone dipropionate; NS: nonsignificant. " : $1=$ no admissions, $2=$ one admission, $3=$ two to four admissions, $4=$ five to 10 admissions, $5=>10$ admissions; ${ }^{\uparrow}: 0=$ no courses, $1=$ one course, $2=$ two courses, $3=$ three to five courses, $4=$ more than five courses, $5=$ continuous oral steroid in the last year; ${ }^{+}$: inhaled corticosteroid dose was transformed into equivalent BDP $\mathrm{mg} \cdot \mathrm{day}^{-1}$; budesonide was considered equivalent to BDP and fluticasone propionate equivalent to twice the dose of BDP.

admissions, patients in group $\mathrm{S}$ were more likely to have been mechanically ventilated.

The dose of inhaled corticosteroids was not different between groups. Although the dose of prednisolone was similar, patients in group $\mathrm{N}$ had more short courses of prednisolone in the last year. The use of inhaled and nebulised short-acting $\beta_{2}$-agonist as rescue medication was similar, but patients in group $\mathrm{N}$ used subcutaneous terbutaline more frequently $(41.4 \%$ versus $10.8 \%, \mathrm{p}<0.01)$.

\section{Lung function}

FVC was lower in patients with severe airflow limitation $(\mathrm{p}<0.001)$ (table 2$)$. TLC was similar but RV was significantly higher in the severe airflow limitation group $(\mathrm{p}<0.001)$. Diffusing capacity was within normal limits. The maximal bronchodilator response was similar but the diurnal PEF variability was greater in group $\mathrm{N}(\mathrm{p}<0.05)$.

\section{Inflammatory markers}

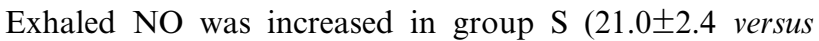
$12.8 \pm 2.3 \mathrm{ppb}, \mathrm{p}<0.05$ ) (fig. 1). Peripheral blood eosinophils were higher in group $\mathrm{S}\left(0.41 \pm 0.06\right.$ versus $0.15 \pm 0.03 \times 10^{9}$ cells $\cdot \mathrm{L}^{-1}$, $\mathrm{p}<0.0001)$. Total serum IgE levels were similar in the two groups (median $133 \mathrm{IU} \cdot \mathrm{mL}^{-1}$ in group $\mathrm{S}$ and $127 \mathrm{IU} \cdot \mathrm{mL}^{-1}$ in group $\mathrm{N}$ ).

\section{Quality of life}

The mean scores in each group show a significant impairment of the overall quality of life, as well as in all three domains, with no differences between the groups (table 3 ).

\section{HRCT evaluation of the airways}

HRCT scans were performed in 34 (of 37) patients in the low FEV1 group and in 27 (of 29) in the normal FEV1 group. Bronchial wall thickening was found in 15 patients $(44.1 \%)$ with severe airflow limitation and in only two $(7.4 \%)$ with normal lung function (fig. $2 ; \mathrm{p}<0.01$ ). Bronchial dilatation was found in 12 patients $(35.3 \%)$ from group $\mathrm{S}$ and three $(11.1 \%)$ from group $\mathrm{N}(\mathrm{p}<0.05)$. Air trapping was found in 21 patients $(61.8 \%)$ in group $\mathrm{S}$ and 13 patients $(50.0 \%)$ in group $\mathrm{N}$ (nonsignificant difference). Separate analysis of these

Table 2. - Lung function tests

\begin{tabular}{|c|c|c|c|}
\hline & Group S & Group N & p-value \\
\hline Patients $\mathrm{n}$ & 37 & 29 & \\
\hline FEV1 $\%$ pred range & $16.6-49.8$ & $81.4-121.0$ & N/A \\
\hline FEV1 $\%$ pred mean & $38.4 \pm 1.3$ & $98.1 \pm 2.0$ & N/A \\
\hline FVC $\%$ pred & $72.6 \pm 2.7$ & $102.1 \pm 2.2^{\S}$ & $<0.001$ \\
\hline TLC $\%$ pred & $111.5 \pm 2.9^{\#}$ & $105.5 \pm 2.2^{\S}$ & NS \\
\hline RV \% pred & $178.2 \pm 7.1^{\#}$ & $113.0 \pm 5.0^{\S}$ & $<0.001$ \\
\hline RV/TLC \% pred & $1.59 \pm 0.04^{\#}$ & $1.06 \pm 0.04^{\S}$ & $<0.001$ \\
\hline Kco $\%$ pred & $98.1 \pm 3.0^{\top}$ & $100.2 \pm 2.7^{\S}$ & NS \\
\hline Maximal bronchodilator response $\%$ FEV1 & $22.2(10.0-39.2)^{+}$ & $13.7(1.1-56.2)^{f}$ & NS \\
\hline PEF variability amplitude $\%$ mean & $12.9(8.1-18.3)^{\S}$ & $19.6(11.9-35.8)^{\# \#}$ & $<0.05$ \\
\hline
\end{tabular}

Data are presented as $\mathrm{n}$, mean \pm SEM or median (interquartile range) unless stated otherwise. FEV1: forced expiratory volume in one second; FVC: forced expiratory volume; TLC: total lung capacity; RV: residual volume; Kco: transfer factor to carbon monoxide; PEF: peak expiratory flow; N/A: not applicable; NS: nonsignificant. ${ }^{\#}: \mathrm{n}=35 ;{ }^{\uparrow}: \mathrm{n}=36{ }^{+}: \mathrm{n}=30 ;{ }^{\S}: \mathrm{n}=28 ;{ }^{f}: \mathrm{n}=26 ;{ }^{\# \#}: \mathrm{n}=22$. 

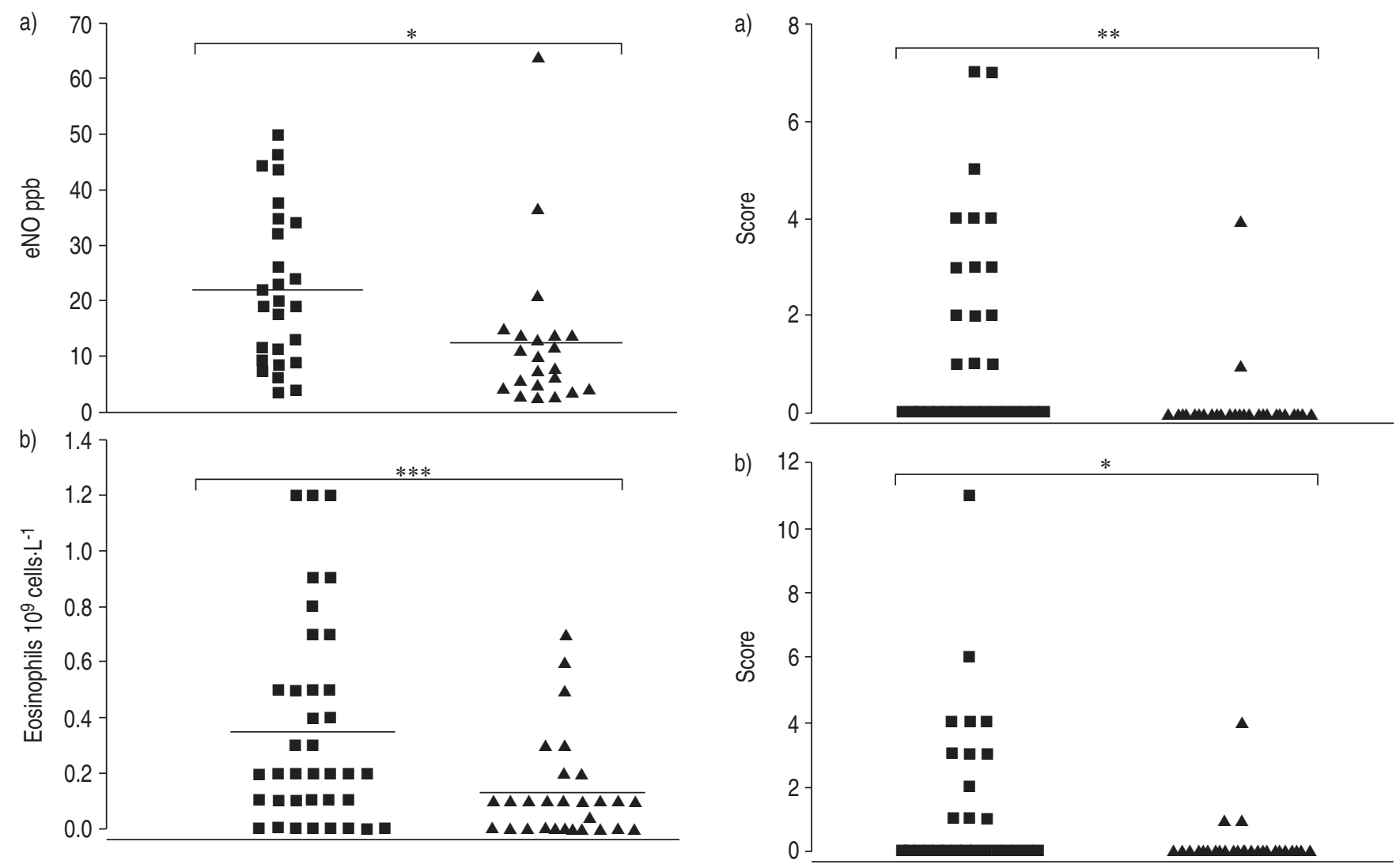

Fig. 1. - Individual scores of a) exhaled NO levels and b) blood eosinophil counts in patients with severe asthma with (forced expiratory volume in one second (FEV 1$)<50 \%(\boldsymbol{\square})$ ) or without $\left(\mathrm{FEV}_{1}>80 \%\right.$ (A)) airflow obstruction. Horizontal bar indicates median. *: $\mathrm{p}<0.05$; $* * *: \mathrm{p}<0.001$.

alterations for each pair of pulmonary lobes showed a nonsignificant higher involvement of lower lobes as compared with upper or middle lobes. Examples of the HRCT abnormalities are shown in figure 3 .

\section{Factors associated with severe airflow limitation}

Peripheral blood eosinophilia, and bronchial wall thickening and bronchial dilatation on HRCT examination were significantly associated with severe persistent airflow limitation (table 4). OR adjusted for age, sex and asthma duration were calculated for several factors (table 5) and blood eosinophilia and bronchial wall thickening were the only factors independently associated with the outcome. When analysis was done including the two significant factors in the same model, they proved to be associated with the presence of persistent airflow limitation (blood eosinophilia: $\mathrm{OR}=24.1$; 95\% CI: 3.0-192.9 and bronchial wall thickening on HRCT: $\mathrm{OR}=18.4 ; 95 \% \mathrm{CI}: 2.3-146.2$ ), independently of each other.

Table 3. - St. George's Respiratory Questionnaire scores

\begin{tabular}{lccc}
\hline & Group S & Group N & p-value \\
\hline Patients n & 37 & 29 & \\
Overall score & $59.57 \pm 3.20$ & $51.70 \pm 3.39$ & NS \\
Symptom & $79.03 \pm 2.26$ & $75.65 \pm 3.22$ & NS \\
Activity & $67.66 \pm 4.30$ & $60.63 \pm 5.31$ & NS \\
Impact & $49.37 \pm 3.55$ & $40.07 \pm 3.28$ & NS \\
\hline
\end{tabular}

Data are presented as mean \pm SEM. NS: nonsignificant.

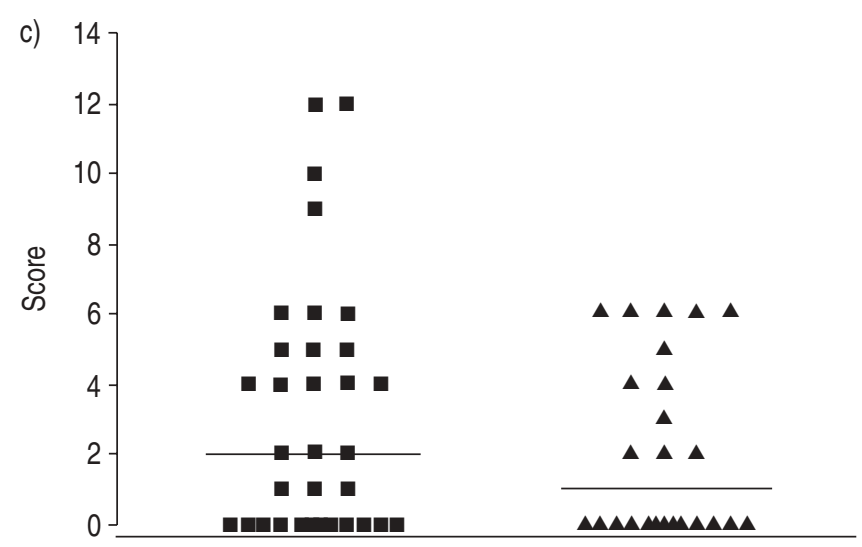

Fig. 2. - Scores for a) bronchial wall thickening, b) bronchial dilatation and c) air trapping measured from high resolution computed tomograms for patients with severe asthma with (FEV1 $<50 \%(\mathbf{\square}))$ or without $(\mathrm{FEV} 1>80 \%(\boldsymbol{\Delta}))$ airflow obstruction. Horizontal bar indicates median. *: $\mathrm{p}<0.05 ; * *: \mathrm{p}<0.01$.

In order to test the robustness of the analysis, the same comparisons and logistic regression analyses were performed with the nonsmokers, and again with nonsmokers and smokers with $<10$ pack-yrs tobacco consumption. Bronchial wall thickening and bronchial dilatation were the only factors significantly associated with the presence of severe airflow obstruction in all populations, including the whole population, the nonsmoking population and the $<10$ pack-yrs population (table 6 ). When adjusted for age, sex and asthma duration, bronchial wall thickening was the only significantly associated factor with the presence of severe persistent airflow obstruction. Thus, the association of bronchial wall thickening with the presence of severe airflow obstruction is independent of age, sex and asthma duration, and is present whether the whole 

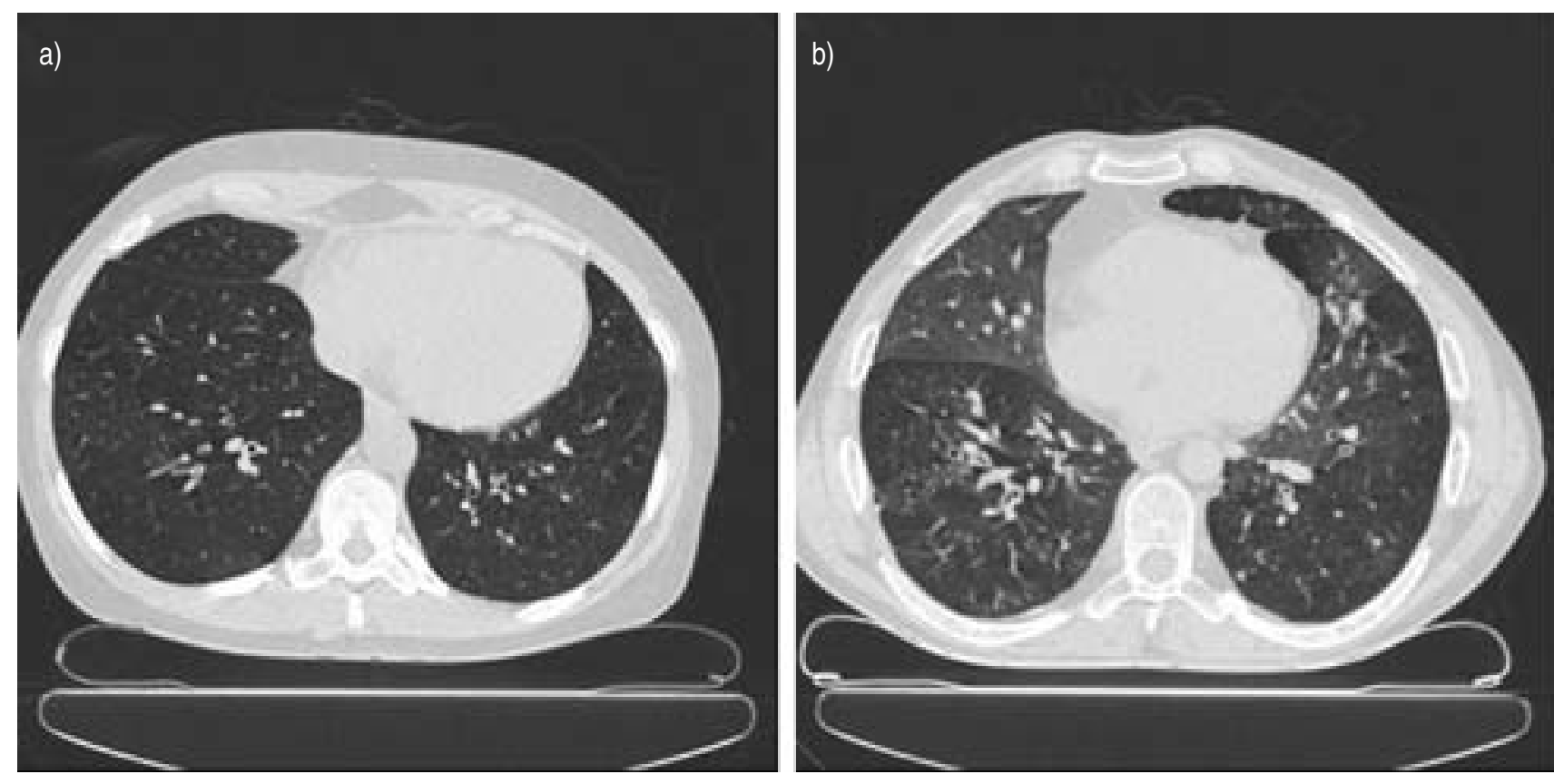

Fig. 3. - High resolution computed tomography of the lungs from two patients with severe asthma with predicted forced expiratory volume in one second $<50 \%$. a) Airway wall thickening and mild dilatation of the intrapulmonary airways in both lower lobes, and b) air-trapping with mosaic pattern, together with bronchial dilatation and thickening of the intrapulmonary airways.

population, the nonsmoking population or the $<10$ pack-yrs population was examined.

\section{Discussion}

In this study of patients with severe asthma, important differences between those with normal lung function and those with severe persistent airflow limitation have been found. Patients have been carefully assessed and characterised in

Table 4.-Crude OR for the presence of severe persistent airflow obstruction

\begin{tabular}{lc}
\hline Atopy & $0.96(0.36-2.54)$ \\
Smoking history & $2.61(0.86-7.95)$ \\
Exhaled NO & $2.71(0.81-9.05)$ \\
Age at onset & $0.71(0.27-1.89)$ \\
Peripheral blood eosinophil & $4.16(1.05-16.52)$ \\
Total IgE & $0.53(0.19-1.44)$ \\
Bronchodilator response & $2.4(0.62-9.27)$ \\
PEF variability & $0.34(0.09-1.29)$ \\
Bronchial thickening & $9.87(2.01-48.46)$ \\
Bronchial dilatation & $4.36(1.09-17.54)$ \\
Air-trapping & $1.62(0.57-4.54)$ \\
\hline
\end{tabular}

Data are presented as OR $(95 \% \mathrm{CI})$. IgE: immunoglobulin E; PEF: peak expiratory flow. terms of diagnosis, severity of asthma, aggravating factors and associated diseases. It was important to make sure that there were no other significant lung diseases apart from asthma in these patients, and many exclusions in the obstructed group was due to the presence of pulmonary comorbidity factors. Severe persistent airflow obstruction was found to be associated with older age, more prolonged disease course, increased peripheral blood eosinophilia and especially bronchial wall thickening on HRCT. The last factor was associated with airflow obstruction independently of various confounding factors and this association was also found when the analysis was performed in nonsmokers as well as in nonsmokers combined with smokers with $<10$ pack-yrs of tobacco consumption.

Table 5. - Adjusted OR (for age, sex and asthma duration) for the presence of severe persistent airflow obstruction.

$\begin{array}{ll}\text { Bronchial thickening } & 8.08(1.31-49.73) \\ \text { Peripheral blood eosinophils } & 6.26(1.27-30.93) \\ \text { Bronchial dilatation } & 2.67(0.53-13.51) \\ \text { Smoking history } & 2.53(0.65-9.87) \\ \text { Exhaled NO } & 2.42(0.55-10.58) \\ \text { Atopy } & 1.26(0.36-4.41) \\ \text { Total IgE } & 0.69(0.19-2.56) \\ \text { Age at onset } & 0.16(0.02-1.36)\end{array}$

Data are presented as adjusted OR $(95 \% \mathrm{CI})$. IgE: immunoglobulin E.

Table 6. - Logistic regression analysis in various populations

\begin{tabular}{|c|c|c|c|}
\hline & Whole & Nonsmoking & $<10$ pack-yrs \\
\hline Bronchial wall thickening & $9.87(2.01-48.4)$ & $22.0(2.47-196.0)$ & $10.39(2.05-52.6)$ \\
\hline Bronchial dilatation & $4.36(1.09-17.5)$ & $5.65(1.02-31.5)$ & $4.26(1.02-17.8)$ \\
\hline Peripheral blood eosinophils & $4.16(1.05-16.5)$ & $3.94(0.70-22.2)$ & $3.43(0.82-14.4)$ \\
\hline Exhaled NO & $2.71(0.81-9.1)$ & $2.67(0.54-13.1)$ & $4.00(0.98-16.3)$ \\
\hline Bronchial wall thickening ${ }^{\#}$ & $8.08(1.31-49.7)$ & $23.46(1.85-297.2)$ & $9.71(1.41-67.0)$ \\
\hline Bronchial dilatation $^{\#}$ & $2.67(0.53-13.5)$ & $3.62(0.45-29.1)$ & $2.54(0.44-14.6)$ \\
\hline
\end{tabular}

Data are presented as OR $(95 \% \mathrm{CI}){ }^{\#}$ : adjusted OR for age, sex and disease duration. 
There were no differences between the groups in terms of atopic status, quality of life scores and the amount of asthma treatment they were taking; though one notable exception was the use of subcutaneous terbutaline, which was more frequent in the nonobstructed group. This reflects the authors' practice of prescribing subcutaneous terbutaline mainly for brittle asthma and not for patients with chronic airflow obstruction. There were no differences in the dose of inhaled corticosteroids used between the two groups, but the doses used were very high with a mean of $3,400 \mu \mathrm{g}$ of beclomethasone equivalent per day. These patients were likely to be overtreated with inhaled corticosteroid therapy given the relatively shallow concentration-response curve. There were significant differences, such as the older age with longer duration of disease of the patients with persistent airflow obstruction, and more importantly these patients, despite having similar rates of hospital admissions, had experienced more episodes of mechanical ventilation for asthma. Diffusing capacity was within normal limits in all patients and HRCT examination showed no evidence of emphysema. Although there was no significant difference in smoking history between the two groups, it is noteworthy that $40.5 \%$ of the obstructed asthmatics were either current or past smokers compared with $20.7 \%$ in the nonobstructed group. However, there were few current smokers in each group and the level of tobacco consumption was low, with only seven patients in the obstructed group and two patients in the group without airflow obstruction having smoked $\geqslant 10$ pack-yrs. Cigarette smoking could be a predisposing factor for chronic airflow obstruction in patients with asthma and is in accordance with the accelerated decline in lung function over time observed in asthmatic smokers [16].

Two indirect markers of inflammation, exhaled NO and blood eosinophil count, were increased in patients with persistent airflow obstruction compared with those with normal lung function. Exhaled NO reflects an aspect of airway inflammation in asthma [17], and there is a correlation with the number of eosinophils in induced sputum or bronchial biopsies in mild asthmatics not on inhaled corticosteroid therapy $[18,19]$. Peripheral blood eosinophilia was significantly associated with severe persistent airflow obstruction in the whole population, but this association was not significant in the nonsmoking population and in the $<10$ pack-yr population. The number of peripheral blood eosinophils has been related to the level of airway inflammation, asthma severity and lung function as measured by FEV1 [20, 21]. A strong association between sputum eosinophilia and persistent airflow limitation has been found in severe asthmatic patients. However, airflow obstruction was defined as an FEV1 of $<75 \%$ pred [9], which is a cut-off point that would include also mild-to-moderate airflow obstruction. The current authors chose a more "severe" limit of $<50 \%$ FEV1 predicted. Persistence of the inflammatory process in the airways of patients with severe asthma has been reported previously [5, 22], and in the authors' studies of severe asthma, a persistence of eosinophils and neutrophils with high levels of eosinophilic cationic protein in induced sputum was found [6].

The most important differences found between the groups relate to airway abnormalities in terms of bronchial wall thickening and dilatation in patients with severe persistent airflow obstruction rather than in those with normal lung function. Bronchial wall thickening was significantly and independently associated with severe persistent airflow limitation. This association was present when the analysis was performed in nonsmoking population and in the $<10$ pack-yr population. Bronchial wall thickening and dilatation have been found to be more frequent in patients with asthma than in healthy subjects [23-25] with reported frequencies varying $16-92 \%$ for bronchial wall thickening and $31-77 \%$ for bronchial dilatation. This variability may be related to the subjective nature of the computed tomography interpretation and to differences in patient populations. The increase in the extent of airways abnormalities (including wall thickening and dilatation) was related to increasing severity and duration of asthma [23, 26, 27]. In cross-sectional studies, either a negative correlation [27] or no correlation [28] has been reported between bronchial wall thickness and FEV1.

The extent to which airway wall remodelling features, such as thickening of subepithelial layer, smooth muscle hypertrophy and hyperplasia, angiogenesis, mucous glands hyperplasia contribute to the bronchial alterations seen on HRCT and to persistent airflow limitation is largely unknown. Airway remodelling has been implicated in the accelerated decline of FEV1 in asthmatics [16] and could contribute to the persistence of airflow limitation despite maximal treatment. Subepithelial fibrosis has been inversely related to FEV1 [29], but there is no evidence as yet for a relationship between FEV1 decline and the degree of subepithelial fibrosis. Eosinophils produce metalloproteinases, collagenase, and growth factors (transforming growth factor- $\beta$ and plateletderived growth factor), which regulate the proliferation of fibroblasts and airway smooth muscle and matrix production from fibroblasts and other stromal tissues [30], suggesting a role for eosinophils in inducing and maintaining airway remodelling in asthma. However, the data indicate that increased peripheral blood eosinophilia and bronchial wall thickening on HRCT were associated with airflow obstruction, independently of each other. This suggests that eosinophilic inflammation is not related to the structural changes in the airways. Other noneosinophilic aspects of the asthmatic inflammation may be related to airway wall remodelling features.

The quality of life scores were similar in the two groups. Previous studies have either reported a negative relationship between quality of life scores and lung function expressed as FEV1 [14, 31, 32] or lack of correlation between the two variables [33]. MOY et al. [34] using the JUNIPER et al. [35] Asthma Quality of Life Questionnaire, showed a weak correlation between the two parameters in mild asthmatics and no correlation in moderate-to-severe asthmatics. These authors found a wide range of quality of life scores for a given level of FEV1 in the moderate-to-severe group, which is similar to the findings in the current study in more severe patients. This may reflect the variability in the patient's adaptation to their disability and the way patients cope with their disease. Other factors, such as the intensity and the persistence of symptoms, may have much greater impact on quality of life than the level of lung function. This is particularly true for severe asthma patients, who experience severe and/or persistent symptoms regardless of persistent airflow limitation.

Patients with severe asthma and severe persistent airflow limitation have certain different characteristics than those with normal lung function, namely longer disease duration, indirect evidence of a persistent inflammatory process, and increased incidence of thickened airways as seen on high resolution computed tomography examination, despite similar impairments in quality of life and similar amounts of treatments for asthma. Persistent airflow obstruction in severe asthma may be associated with a greater degree of inflammation and with structural abnormalities in the airways.

\section{References}

1. Chung KF, Godard P, Adelroth E, et al. Difficult/therapyresistant asthma: the need for an integrated approach to 
define clinical phenotypes, evaluate risk factors, understand pathophysiology and find novel therapies. ERS Task Force on Difficult/Therapy-Resistant Asthma. European Respiratory Society. Eur Respir J 1999; 13: 1198-1208.

2. American Thoracic Society. Proceedings of the ATS workshop on refractory asthma: current understanding, recommendations, and unanswered questions. Am J Respir Crit Care Med 2000; 162: 2341-2351.

3. Godard P, Chanez P, Siraudin L, Nicoloyannis N, Duru G. Costs of asthma are correlated with severity: a 1-yr prospective study. Eur Respir J 2002; 19: 61-67.

4. Ayres JG, Miles JF, Barnes PJ. Brittle asthma. Thorax 1998; 53: 315-321.

5. Wenzel SE, Szefler SJ, Leung DY, Sloan SI, Rex MD, Martin RJ. Bronchoscopic evaluation of severe asthma. Persistent inflammation associated with high dose glucocorticoids. Am J Respir Crit Care Med 1997; 156: 737-743.

6. Jatakanon A, Uasuf C, Maziak W, Lim S, Chung KF, Barnes PJ. Neutrophilic inflammation in severe persistent asthma. Am J Respir Crit Care Med 1999; 160: 1532-1539.

7. Redington AE, Howarth PH. Airway wall remodelling in asthma. Thorax 1997; 52: 310-312.

8. Kraft M, Djukanovic R, Wilson S, Holgate ST, Martin RJ. Alveolar tissue inflammation in asthma. Am J Respir Crit Care Med 1996; 154: 1505-1510.

9. ten Brinke A, Zwinderman AH, Sterk PJ, Rabe KF, Bel EH. Factors associated with persistent airflow limitation in severe asthma. Am J Respir Crit Care Med 2001; 164: 744-748.

10. Robinson DS, Campbell DA, Durham SR, Pfeffer J, Barnes PJ, Chung KF. Systematic assessment of difficult-to-treat asthma. Eur Respir J 2003; 22: 478-483.

11. Stirling RG, Kharitonov SA, Campbell D, et al. Increase in exhaled nitric oxide levels in patients with difficult asthma and correlation with symptoms and disease severity despite treatment with oral and inhaled corticosteroids. Asthma and Allergy Group. Thorax 1998; 53: 1030-1034.

12. Quanjer PH, Tammeling GJ, Cotes JE, et al. Symbols, abbreviations and units. Working Party Standardization of Lung Function Tests, European Community for Steel and Coal. Eur Respir J 1993; 16: 85-100.

13. Higgins BG, Britton JR, Chinn S, et al. The distribution of peak expiratory flow variability in a population sample. $\mathrm{Am}$ Rev Respir Dis 1989; 140: 1368-1372.

14. Jones PW, Quirk FH, Baveystock CM, Littlejohns P. A selfcomplete measure of health status for chronic airflow limitation. The St. George's Respiratory Questionnaire. Am Rev Respir Dis 1992; 145: 1321-1327.

15. Carr DH, Hibon S, Rubens M, Chung KF. Peripheral airways obstruction on high-resolution computed tomography in chronic severe asthma. Respir Med 1998; 92: 448-453.

16. Lange P, Parner J, Vestbo J, Schnohr P, Jensen GA. 15-year follow-up study of ventilatory function in adults with asthma. N Engl J Med 1998; 339: 1194-1200.

17. Kharitonov SA, Yates D, Robbins RA, Logan-Sinclair R, Shinebourne EA, Barnes PJ. Increased nitric oxide in exhaled air of asthmatic patients. Lancet 1994; 343: 133-135.

18. Lim S, Jatakanon A, John M, Gilbey T, et al. Effect of inhaled budesonide on lung function and airway inflammation. Assessment by various inflammatory markers in mild asthma. Am J Respir Crit Care Med 1999; 159: 22-30.

19. Jatakanon A, Kharitonov S, Lim S, Barnes PJ. Effect of differing doses of inhaled budesonide on markers of airway inflammation in patients with mild asthma. Thorax 1999; 54: 108-114.

20. Bousquet J, Chanez P, Lacoste JY, et al. Eosinophilic inflammation in asthma. N Engl J Med 1990; 323: 10331039.

21. Ulrik CS. Peripheral eosinophil counts as a marker of disease activity in intrinsic and extrinsic asthma. Clin Exp Allergy 1995; 25: 820-827.

22. Wenzel SE, Schwartz LB, Langmack EL, et al. Evidence that severe asthma can be divided pathologically into two inflammatory subtypes with distinct physiologic and clinical characteristics. Am J Respir Crit Care Med 1999; 160: 10011008.

23. Paganin F, Trussard V, Seneterre E, et al. Chest radiography and high resolution computed tomography of the lungs in asthma. Am Rev Respir Dis 1992; 146: 1084-1087.

24. Park CS, Muller NL, Worthy SA, Kim JS, Awadh N, Fitzgerald M. Airway obstruction in asthmatic and healthy individuals: inspiratory and expiratory thin-section CT findings. Radiology 1997; 203: 361-367.

25. Lynch DA, Newell JD, Tschomper BA, Cink TM, Newman LS, Bethel R. Uncomplicated asthma in adults: comparison of CT appearance of the lungs in asthmatic and healthy subjects. Radiology 1993; 188: 829-833.

26. Paganin F, Seneterre E, Chanez P, et al. Computed tomography of the lungs in asthma: influence of disease severity and etiology. Am J Respir Crit Care Med 1996; 153: $110-114$

27. Niimi A, Matsumoto $\mathrm{H}$, Amitani $\mathrm{R}$, et al. Airway wall thickness in asthma assessed by computed tomography. Relation to clinical indices. Am J Respir Crit Care Med 2000; 162: 1518-1523.

28. Boulet L, Belanger M, Carrier G. Airway responsiveness and bronchial-wall thickness in asthma with or without fixed airflow obstruction. Am J Respir Crit Care Med 1995; 152: 865-871.

29. Minshall EM, Leung DY, Martin RJ, et al. Eosinophilassociated TGF-beta1 mRNA expression and airways fibrosis in bronchial asthma. Am J Respir Cell Mol Biol 1997; 17: 326-333.

30. Busse W, Elias J, Sheppard D, Banks-Schlegel S. Airway remodeling and repair. Am J Respir Crit Care Med 1999; 160: 1035-1042.

31. Barley EA, Jones PW. A comparison of global questions versus health status questionnaires as measures of the severity and impact of asthma. Eur Respir J 1999; 14: 591616.

32. Barley EA, Quirk FH, Jones PW. Asthma health status measurement in clinical practice: validity of a new short and simple instrument. Respir Med 1998; 92: 1207-1214.

33. Juniper EF, Norman GR, Cox FM, Roberts JN. Comparison of the standard gamble, rating scale, AQLQ and SF-36 for measuring quality of life in asthma. Eur Respir J 2001; 18: $38-44$.

34. Moy ML, Israel E, Weiss ST, Juniper EF, Dube L, Drazen JM. Clinical predictors of health-related quality of life depend on asthma severity. Am J Respir Crit Care Med 2001; 163: 924-929.

35. Juniper EF, Guyatt GH, Epstein RS, Ferrie PJ, Jaeschke R, Hiller TK. Evaluation of impairment of health related quality of life in asthma: development of a questionnaire for the use of clinical trials. Thorax 1992; 47: 76-83. 